\title{
RANCANG BANGUN SISTEM KENDALI JARAK JAUH LAMPU MENGGUNAKAN THINGSBOARD BERBASIS IOT
}

\author{
Yuswandari $^{1}$, Haris Yuana ${ }^{2}$ \\ 1,2 Jurusan Sistem Komputer, Fakultas Teknologi Informasi, Universitas Islam Balitar \\ ${ }^{1}$ yuswandari08@gmail, ${ }^{2}$ harisyuana2010@gmail.com
}

\begin{abstract}
Abstrak
Internet menyediakan berbagai fungsi dan fasilitas yang dapat digunakan sebagai suatu media informasi dan komunikasi yang canggih. Perkembangan teknologi yang bisa dimanfaatkan dari adanya koneksi internet ini adalah bisa mengakses peralatan elektronik seperti lampu ruangan yang dapat dioperasikan dengan cara online melalui website. Penelitian ini dilatar belakangi oleh perlunya suatu sistem kendali jarak jauh yang efesien dan optimal dalam penggunaannya di era globalisasi ini. Dengan kenyataan saat ini maka dituntut untuk dapat menyelesaikan permasalahan yang ada dengan memanfaatkan kecanggihan teknologi serta efiesiensi dalam penggunaannya. Dengan adanya keperluan tersebut muncul sebuah pemikiran untuk membuat sistem kendali jarak jauh lampu menggunakan thingsboard berbasis IoT. ThingsBoard adalah platform IoT open-source untuk pengumpulan data, pemrosesan, visualisasi, dan manajemen perangkat. Dalam penelitian ini menggunakan metode $R$ \& D karena hasil akhir penelitian ini akan menghasilkan produk rancang bangun sistem kendali jarak jauh lampu berbasis IoT. Hasil penelitian yang diperoleh adalah lampu dapat menyala sesuai dengan perintah melalui thingsboard. Web server thingsboard dapat berjalan dengan baik. Web server Thingsboard dan program NodeMCU dapat terhubung yaitu dengan menggunakan token dari Thingsboard. Sistem kendali jarak jauh lampu akan dapat berjalan apabila nodemcu dan perangkat untuk kendali (smartphone atau komputer) berada dalam satu jaringan wifi.
\end{abstract}

Kata kunci : Lampu, NodeMcu, ThingsBoard

\section{Pendahuluan}

Lampu merupakan alat bantu penerangan bagi manusia, diantara banyak jenis lampu yang tersebar di seluruh dunia salah satunya adalah lampu pijar. Di dalam sebuah rumah, hotel atau perkantoran banyak hal dimana pegawai terlalu sibuk dengan pekerjaan mereka. Hal ini membuat mereka melupakan hal kecil dalam suatu ruangan kerja. Lampu di dalam ruang kerja misalnya, sering sekali di pagi hari lampu tidak dimatikan, kemudian malam hari lampu lupa dihidupkan.

Penelitian ini dilatar belakangi oleh perlunya suatu sistem kendali jarak jauh yang efesien dan optimal dalam penggunaannya di era globalisasi ini. Perkembangan ilmu pengetahuan dan teknologi sangat pesat, sejalan dengan hal tersebut permasalahan yang dihadapi juga semakin kompleks. Dengan kenyataan saat ini maka dituntut untuk dapat menyelesaikan permasalahan yang ada dengan memanfaatkan kecanggihan teknologi serta efiesiensi dalam penggunaannya. Dengan adanya keperluan tersebut muncul sebuah pemikiran untuk membuat sistem kendali jarak jauh lampu menggunakan thingsboard berbasis IoT.

Berdasarkan uraian di atas, maka peneliti mengambil judul penelitian "Rancang Bangun
Sistem Kendali Jarak Jauh Lampu Menggunakan Thingsboard Berbasis IoT".

\section{Tinjauan Pustaka}

Dalam penelitan sistem kendali jarak jauh lampu berbasis IoT dengan ESP8266 ini diharapkan dapat membantu dalam pengehematan penggunaan listrik. Penerapan sistem kendali jarak jauh lampu berbasis IoT dengan ESP8266 di maksutkan agar para pengguna baik perkantoran maupun rumah tangga dapat menekan penggunaan listrik yang berlebih karena sering lupa mematikan lampu. Adapun sebelumnya terdapat beberapa penelitian terdahulu yang digunakan sebagai reverensi. Penelitian terdahulu ini bertujuan untuk mengidentifikasi metode yang pernah dilakukan, menghindari kesamaan dalam pembuatan, mengidentifikasi metode, memperbaiki metode yang telah dibuat. Maka dalam tinjauan pustaka ini mencantumkan beberapa penelitian terdahulu.

Pertama, penelitian yang dilakukan Iswanto dan Gandi (2018) yang berjudul "Perancangan Dan Implementasi Sistem Kendali Lampu Ruangan Berbasis IotT (Internet of Things) Android (Studi Kasus Universitas Nurtanio)". Penelitian tersebut mengembangkan sistem kendali lampu ruangan yang 
dapat dikendalikan melalui android. Hasil dari penelitian tersebut adalah dengan dibangunnya aplikasi ini pengguna di Universitas Nurtanio untuk menyalakan dan mematikan lampu dari jarak jauh. Pengguna hanya diminta untuk menekan tombol yang ada pada aplikasi android yang dibangun untuk melakukan perintah menyalakan dan mematikan lampu dengan memanfaatkan koneksi internet.

Persamaan antara penelitian ini dengan penelitian yang dilakukkan oleh Iswanto dan Gandi. Pertama berkaitan dengan objek penelitian yang digunakan yaitu sistem kendali lampu yang berbasis IoT. Kedua, persamaannya yaitu menggunakan sistem kendali berupa arduino.

Perbedaan antara penelitian ini dengan penelitian yang dilakukan oleh Iswanto dan Gandi. Untuk penelitian yang dilakukan oleh Iswanto dan Gandi hanya dapat dioperasikan melalui android, sedangkan pada penelitian ini bisa dioperasikan melalui komputer maupun android.

\subsection{Thingsboard}

Thingsboard adalah sebuah IoT (Internet of Things), yaitu sebuah web server yang akan mengolah data output dari Arduino Uno untuk ditampilkan dalam bentuk grafik. Sistem ini akan menampilkan data output berupa kondisi real time pada sistem monitoring yang dibuat penulis berupa grafik dan chart (Alfaviega,2018).

ThingsBoard adalah platform IoT open-source untuk pengumpulan data, pemrosesan, visualisasi, dan manajemen perangkat. ThingsBoard memungkinkan konektivitas perangkat melalui protokol IoT standar industri seperti MQTT, CoAP dan HTTP dan mendukung penyebaran cloud dan lokal. ThingsBoard menggabungkan skalabilitas, toleransi kesalahan dan kinerja sehingga tidak akan pernah kehilangan data.

\subsection{NodeMCU}

NodeMCU ESP-12E merupakan mikrokontroler yang telah terintegrasi dengan modul Wi-Fi dan termasuk jenis ESP8266, tipe yang digunakan yaitu ESP-12E berbasis firmware eLua. Pada NodeMCU juga sudah dilengkapi dengan tombol reset, flash, dan memiliki IC regulator $3.3 \mathrm{~V}$ bertipe AMS1117 agar dapat bekerja dengan tegangan masukan lebih dari 5V. NodeMCU menggunakan Bahasa pemorgamanan eLua yang merupakan paket dari modul ESP8266 (adam,2019).

\section{Metode Penelitian}

Lokasi penelitian untuk proses pembuatan produk, validasi, dan revisi dilakukan di Program Pendidikan Sistem Komputer, Fakultas Teknologi Informasi, Universitas Islam Balitar. Serta di rumah milik Umi Nafingah yang berlokasi di Dsn. Taruban rt 02 rw 03 Ds. Tegalasri Kec. Wlingi Kab. Blitar untuk melakukan pengujian ke pengguna, pemilihan tempat pengujian ini dikarena pemilik rumah memiliki kegiatan diluar rumah seperti bekerja dan pulang hingga malam atau sore hari. Waktu yang digunakan dalam penelitian ini kurang lebih 6 bulan, mulai bulan Januari 2020 sampai Juli 2020.

Metode penelitian yang digunakan adalah metode penelitian dan pengembangan (Research and Development). Metode penelitian Research and Development (R\&D) adalah metode penelitian yang digunakan untuk menghasilkan produk tertentu dan menguji keefektifan produk tersebut. Untuk menghasilkan produk tertentu digunakan penelitian yang bersifat analisis kebutuhan dan untuk menguji keefektifan produk tersebut supaya dapat berfungsi di masyarakat luas, maka diperlukan penelitian untuk menguji keefektifan produk tersebut Sugiyono (2011 :297). Dalam penelitian ini mengunakan metode R \& D karena hasil akhir penelitian ini akasn menghasilkan produk rancang bangun sistem kendali jarak jauh lampu berbasis IoT.

Alur dalam penelitian dan pengembangan menurut Sugiyono (2011 :298) dapat digambarkan sebagai berikut.

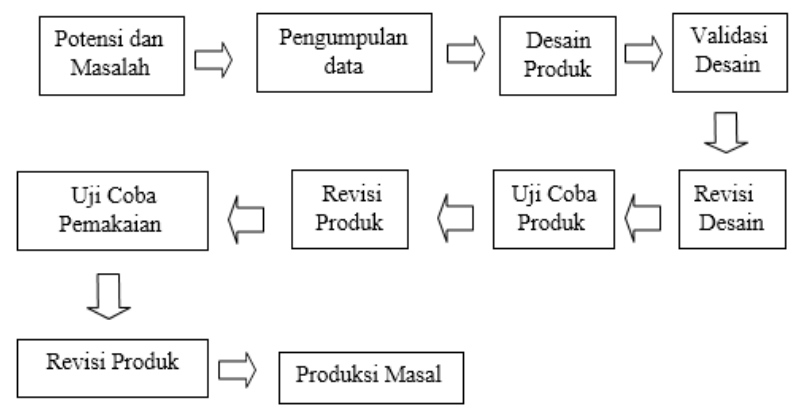

Gambar 1. Diagram Prosedur Penelitian $R \& D$

Dari 10 langkah yang dikembangakan oleh Sugiyono hanya 6 langkah yang akan diadaptasikan dalam penelitian kali ini yaitu langkah 1 sampai dengan 6 , sebagai berikut:

\subsection{Potensi Masalah}

Perkembangan jaman yang mempengaruhi kemampuan berpikir manusia untuk menciptakan teknologi yang dapat membantu program penghematan energi. Dengan adanya keperluan tersebut muncul sebuah pemikiran untuk membuat sistem kendali jarak jauh yang efisien dalam menghemat energi listrik yaitu dengan lampu yang dapat dimonitoring dan dinyala matikan dari jarak jauh melalui web server. Sistem kendali jarak jauh ini akan bekerja dengan cara dikendalikan dan dimonitoring melalui komputer maupun smartphone dengan menggunakan Thingsboard. Input yang digunakan berupa image button (on/off lampu) yang ada pada Thingsboard. 


\subsection{Pengumpulan Data}

Teknik pengumpulan data dalam penelitian ini adalah sebagai berikut:

1. Studi literatur, dilakukan guna mendapatkan pemahaman mengenai otomatisasi menggunakan Arduino dapat terhubung internet melalui Thingsboard yang dibuat. Termasuk didalamnya bagaimana cara kerja Thingsboard dan cara kerja Arduino. Sumber pengetahuan yang digunakan dalam membuat kaidah/aturan adalah dengan menggunakan pengetahuan dari buku, jurnal dan artikel.

2. Observasi, Observasi adalah metode pengumpulan data yang kompleks karena melibatkan berbagai faktor dalam pelaksanaannya.

\subsection{Desain Produk}

Desain Produk atau model pengembangan yang dihasilkan adalah terciptanya sistem kendali lampu yang dapat dikendalikan jarak jauh melalui Thingsboard. Pada perancangan sistem ini, petugas melakukan input dari aplikasi kendali yang ada pada smartphone android. Input yang digunakan berupa image button (on/off lampu). Data yang diinputkan kemudian dikirim ke webserver, melalui koneksi internet. Selanjutnya data dikirimkan dari webserver ke modul ESP8266 yang terkoneksi dengan internet, kemudian diterima oleh modul Wi-Fi ESP8266. Data serial yang dikirimkan oleh modul $W i-F i$ ke mikrokontroller selanjutnya diterjemahkan oleh mikrokontroller menjadi data pararel. Data pararel yang dihasilkan oleh mikrokontroler diteruskan ke relay melalui indikator led pada relay untuk memastikan lampu on, maka led juga akan menyala dan begitu juga sebaliknya. Kemudian relay akan meneruskan data yang digunakan untuk on/off lampu. Seperti terlihat pada gambar di bawah ini

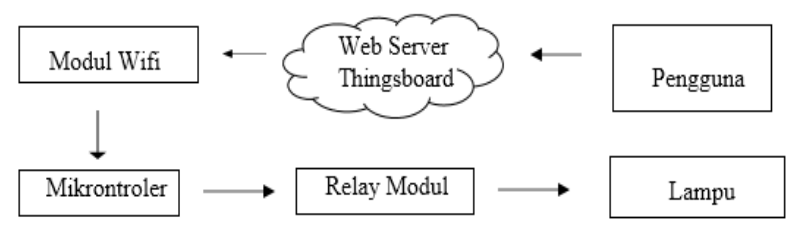

Gambar 2. Diagram Desain Produk

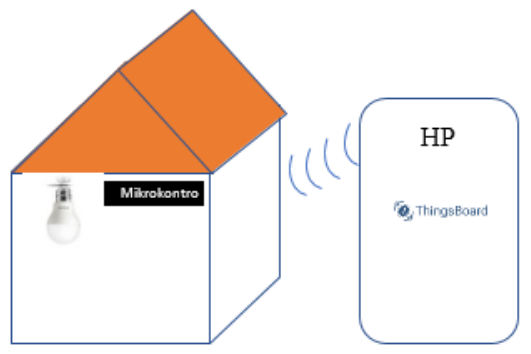

Gambar 3. Desain Rancang Bangun
Dari gambar 3 dapat diketahui bahwa letak lampu berada di dalam ruangan. Letak mikrokontroler dengan lampu bisa berjauhan, namun pada penelitian ini lampu diletakkan berdekatan dengan mikrokontroler agar mudah dalam pengecekan. Lampu dihubungkan menggunakan kabel ke mikrokontroler, untuk panjang kabel menyesuaikan keperluan. Prinsip kerja sistem ini adalah lampu dapat menyala apabila pengguna melakukan perintah mati atau hidup melalui android yang sudah tersambung ke ThingBoard.

Perancangan alat yang harus dilakukan adalah dengan menentukan logika yang akan diterapkan pada sistem kendali lampu dan membuat algoritmanya, yang nantinyaakan di implementasikan menggunakan Arduino IDE.

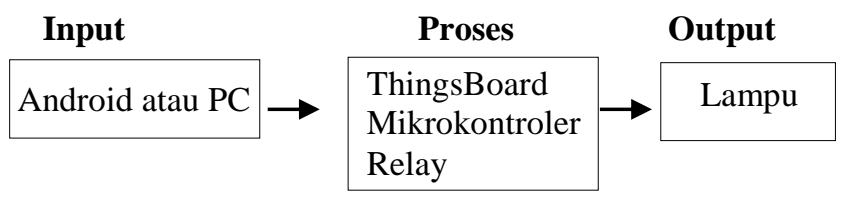

Gambar 4. Blok Diagram Alat

Flowchart algoritma program pada perangkat lunak yang akan ditanam didalam mikrokontroller Arduino UNO adalah sebagai berikut:

Pertama adalah memulai dengan memproses inisialisasi nodemcu. Selesai proses inisialisasi kemudian melihat kondisi koneksi internet pada nodemcu, jika belum terkoneksi dengan internet maka mengulang kembali pada proses inisialisasi namun jika sudah terkoneksi maka lanjut dengan memasukan data oleh pengguna. Memasukkan data ini bisa dari android ataupun komputer. Selesai memasukkan data kemudian akan dikirim ke data server Thingsboard untuk di proses.

Selanjunya data yang sudah selesai di proses Thingsboard akan di terima nodemcu melalui komunikasi serial. Langkah selanjutnya melihat dua kondisi yaitu lampu ruang tamu dan lampu kamar. Kondisi pertama jika perintah yang dimasukan lampu ruang tamu on maka relay 1 on dan lampu menyala, namun jika yang dimasukkan lampu ruang tamu perintah off maka relay 1 off dan lampu mati. Kondisi kedua jika perintah yang dimasukkan lampu kamar tidur on maka relay 2 on dan lampu menyala, namun jika yang dimasukkan perintah lampu kamar off maka relay 2 off dan lampu mati. 


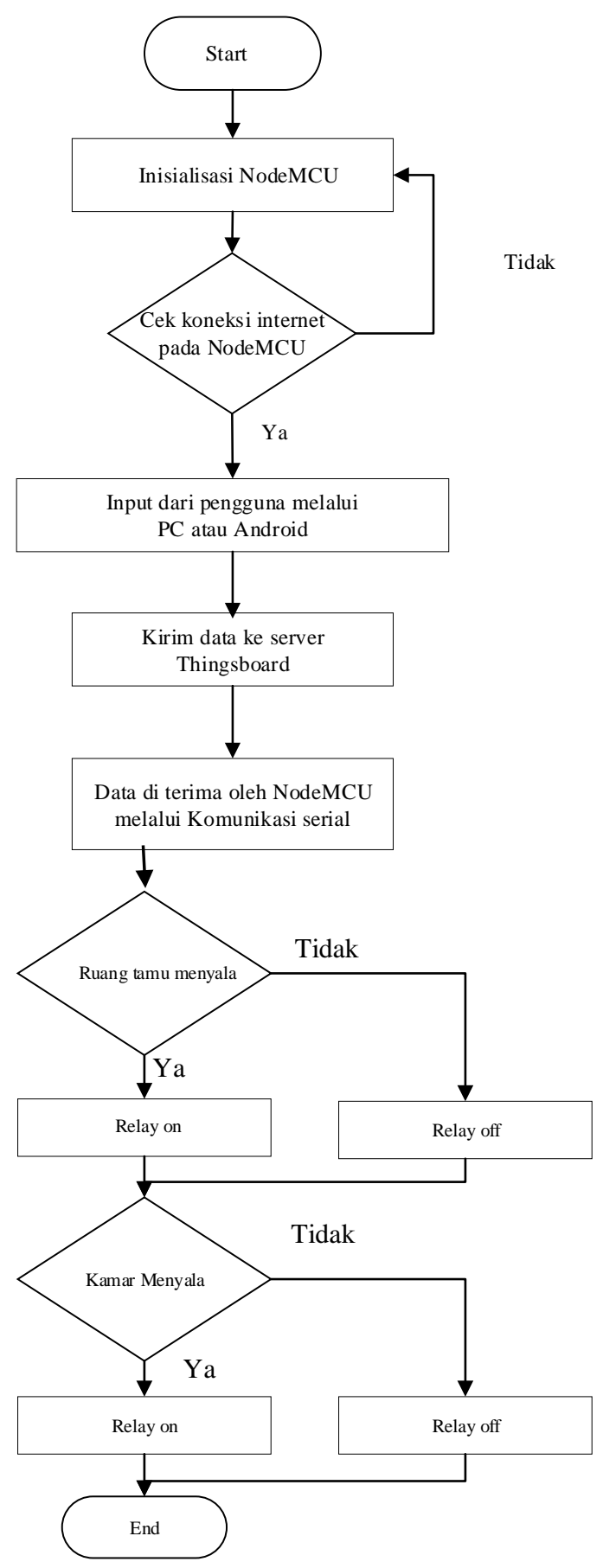

Gambar 5. Flowchart Sistem Kendali Lampu

\subsection{Validasi Desain}

Validasi desain merupakan proses kegiatan untuk menilai apakah rangcangan produk lebih efektif atau tidak, produk dalam hal ini adalah sistem kendali lampu yang dapat dikendalikan jarak jauh melalui ThingsBoard. Validasi yang dilakukan dengan meminta pakar dalam bidang penelitian ini berbagai pertimbangan untuk menilai rancangan produk tersebut.

\subsection{Perbaikan Desain}

Setelah desain produk berupa rancangan alat di evaluasi dan di analisis oleh para pakar maka akan menghasilkan berbagai masukkan dan kelemahan dari rangcangan alat tersebut. Dari hasil inilah kemudian akan dilakukan beberapa perubahan yang menjadikan alat ini menjadi berkualitas. Jika tidak terdapat revisi maka peneliti melanjutkan ke langkah penelitian yang selanjutnya.

\subsection{Uji Coba Produk}

Uji coba produk yang akan peneliti lakukan, yang pertama menguji semua komponen yang akan digunakan dalam pembuatan produk, selanjutnya menguji unjuk kerja alat dengan tingkat keandalan alat.

\section{Hasil}

Implementasi perangkat keras kendali lampu ini dimulai dengan perakitan tiap komponen. NodeMCU digunakan untuk kendali jarak jauh di hubungan ke relay menggunakan kabel jumper. Implementasi perangkaian dapat di lihat pada gambar berikut

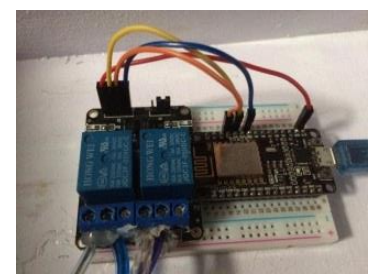

\section{Gambar 6. Rangkaian NodeMCU dan Relay}

Pada gambar 6 rangkaian alat menggunakan relay 2 chanel. Relay 2 chanel memiliki 4 pin di sebelah kanan yang akan di sambungkan antara lain pin VCC relay di sambungkan ke pin 3.3 NodeMCU, pin IN2 relay di sambungkan ke pin D4 NodeMCU, pin IN1 di sambungkan ke pin D3 NodeMCU dan pin GND disambungkan ke pin GND nodemcu.

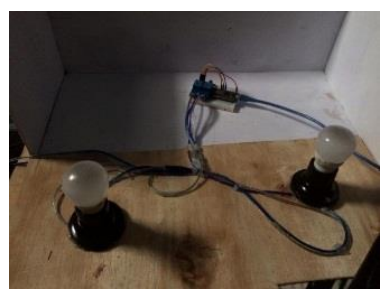

Gambar 7. Rangkaian Alat

Rangkaian NodeMCU relay kemudian di sambungkan dengan 1 steker dan 2 pitingan yang sudah terpasang lampu dengan daya masing-masing 3 watt. Fungsi steker yaitu untuk memberi tegangan lampu dengan cara dicolokan ke stop kontak. 
Rangkain steker dan lampu ini dibuat seperti gambar berikut:

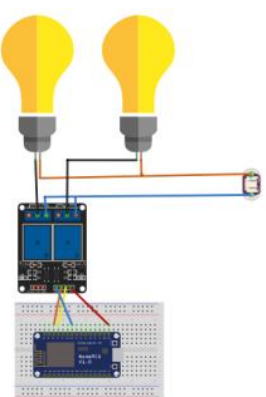

Gambar 8. Rangkain Sistem

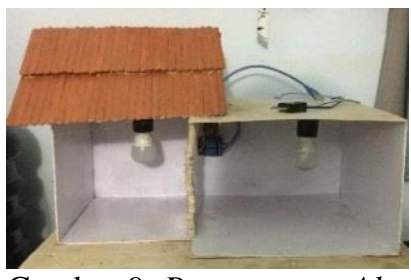

Gambar 9. Pemasangan Alat

Pemasangan alat ini dengan cara di tempelkan dengan kerangka rumah yang terbuat dari triplek. Kerangka rumah ini berukuran $25 \mathrm{~cm}$ x $50 \mathrm{~cm}$. Dibuat seperti kerangka rumah agar memudahkan dalam pengilustrasian apabila alat di pasang di tempat yang sebenarnya.

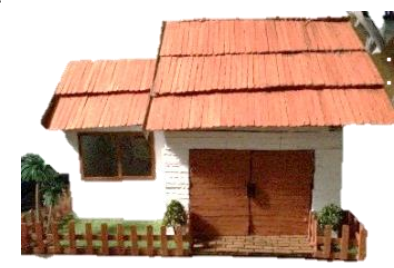

Gambar 10. Ilustrasi Rumah

ESP8266 Demo Device ini digunakan sebagai server sistem kendali jarak jauh lampu. Tampilan menu Esp8266 Demo Device sebagai berikut:

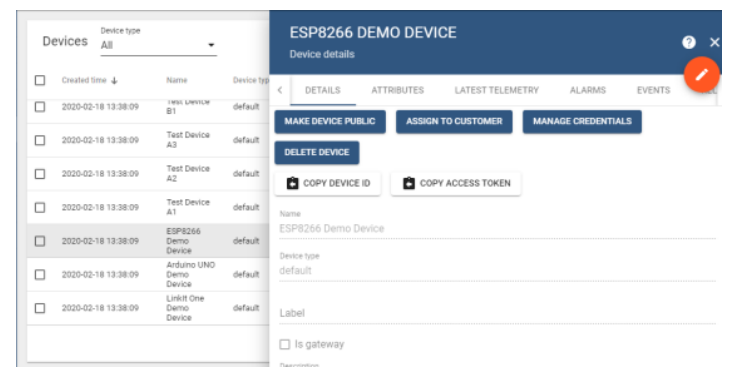

Gambar 11. Esp8266 Demo Device

Pada menu esp8266 demo device ini sudah disediakan token. Fungsi token ini sebagai untuk membuka token perlu memilih manage credentials maka akan ada keterangan acces token. Token disalin dan di tambahkan ke program sistem kendali jarak jauh lampu di arduino IDE. Tampilan halaman device Credentials sebagai berikut:

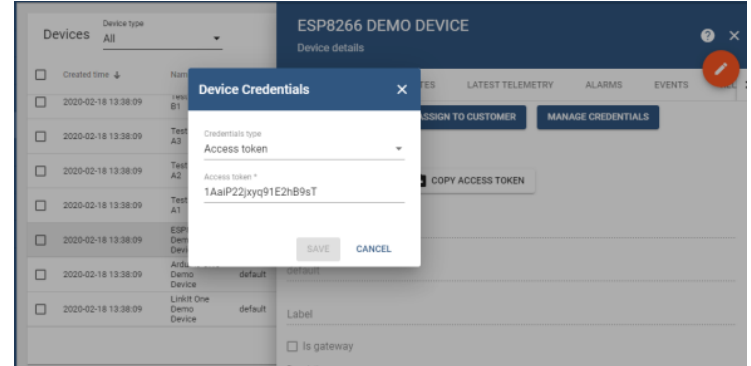

Gambar 12. Halaman Device Credentials

Selesai copy token, token di definisikan di program Arduino IDE dengan cara \#define TOKEN agar token dapat terbaca program. Berikut adalah gambar token yang ada di program:

\section{\#define TOKEN "1AaiP22jxyq91E2hB9sT"}

Gambar 13. Token ThingsBoard di Program Arduino IDE

Sistem kendali jarak jauh lampu menggunakan ThingsBoard menggunakan kontrol langsung dari web server ThingsBoard. Kontrol sistem kendali jarak jauh ini dengan membuat tombol kontrol di menu dashboard. Tampilan halaman dashboard seperti berikut:

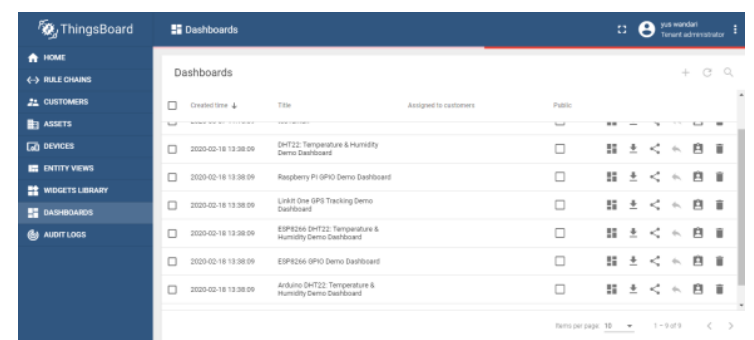

Gambar 14. Halaman DashBoard ThingsBoard

Pada menu dashboard banyak pilihan menu, sedangkan untuk membuat tombol kontrol dengan cara membuka detail dasboard pada Esp8266 Demo. Detail Esp8266 Demo sudah terbuka, kemudian memilih open dashboard. Berikut adalah gambar tampilannya:

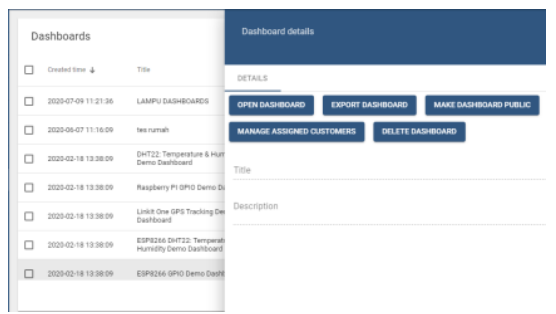

Gambar 15. Halaman Esp8266 Demo Dashboard

Selesai open dashboar maka akan tampil tombol kontrol yang digunakan untuk kendali jarak jauh lampu. Tampilan tombol kontrol sebagai berikut: 


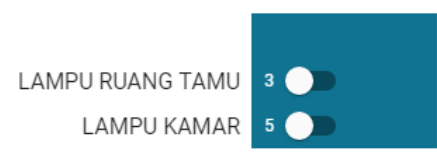

Gambar 16. Halaman tombol control Esp8266

Langkah selanjutnya dalam penelitian adalah pengujian alat. Tujuan pengujian alat ini untuk menemukan kesalahan dan kekurangan pada sistem kendali jarak jauh lampu yang diuji. Pengujian tersebut dimaksudkan untuk mengetahui sistem yang dibuat sudah memenuhi kriteria yang sesuai dengan tujuan perancangan yang dibuat. Pengujian yang dilakukan yaitu pengujian menyalakan lampu dengan web server ThingsBoard. Pada gambar 17 lampu dalam keadaa mati semua.

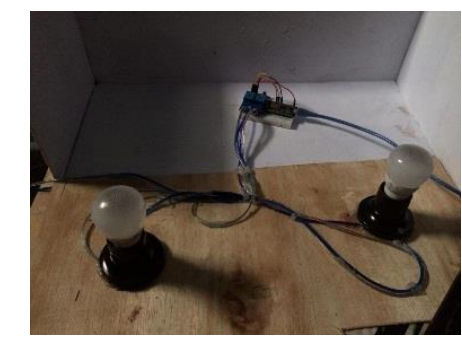

Gambar 17. Keadaan Awal Lampu

Pengujian pertama dilakukan dengan dengan menyalakan satu lampu kiri. Pada percobaan ini lampu berhasil menyala. Berikut adalah gambar percobaanya:

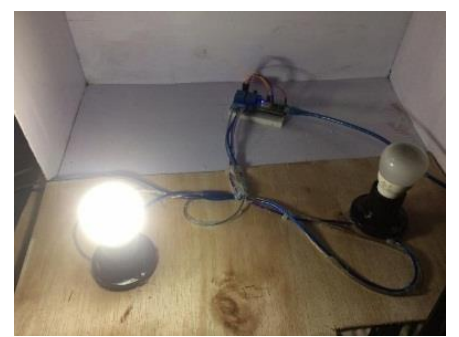

Gambar 18. Pengujian Pertama

Pengujian kedua dilakukan dengan menyalakan lampu sebelah kanan. Pada percobaan kedua lampu berhasil menyala. Berikut adalah gambar percobaanya:

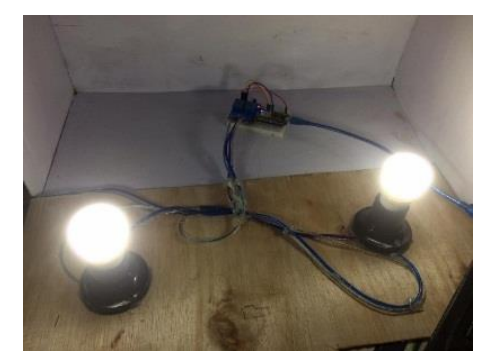

Gambar 19. Pengujian Kedua

Pengujian alat dengan jarak tertentu ini melalui ThingsBoard yang berjalan di android.
Setelah perangkat sudah terkoneksi maka akan diuji setiap lampu. Hasil terdapat pada tabel berikut:

Tabel 1. Uji Lampu

\begin{tabular}{|c|c|c|c|c|}
\hline No. & Tombol & Jarak & Kondisi & Hasil \\
\hline 1. & $\begin{array}{l}\text { Lampu } \\
\text { Ruang } \\
\text { Tamu }\end{array}$ & $\begin{array}{l}1 \\
\text { meter }\end{array}$ & $O N$ & NYALA \\
\hline 2. & $\begin{array}{l}\text { Lampu } \\
\text { Kamar }\end{array}$ & $\begin{array}{l}1 \\
\text { meter }\end{array}$ & $O F F$ & MATI \\
\hline 3. & $\begin{array}{l}\text { Lampu } \\
\text { Ruang } \\
\text { Tamu }\end{array}$ & $\begin{array}{l}1 \\
\text { meter }\end{array}$ & $O N$ & NYALA \\
\hline 4. & $\begin{array}{l}\text { Lampu } \\
\text { Kamar }\end{array}$ & $\begin{array}{l}1 \\
\text { meter }\end{array}$ & $O F F$ & MATI \\
\hline 5. & $\begin{array}{l}\text { Lampu } \\
\text { Ruang } \\
\text { Tamu }\end{array}$ & $\begin{array}{l}20 \\
\text { meter }\end{array}$ & $O N$ & NYALA \\
\hline 6. & $\begin{array}{l}\text { Lampu } \\
\text { Kamar }\end{array}$ & $\begin{array}{l}20 \\
\text { meter }\end{array}$ & $O F F$ & MATI \\
\hline 7. & $\begin{array}{l}\text { Lampu } \\
\text { Ruang } \\
\text { Tamu }\end{array}$ & $\begin{array}{l}20 \\
\text { meter }\end{array}$ & $O N$ & NYALA \\
\hline 8. & $\begin{array}{l}\text { Lampu } \\
\text { Kamar }\end{array}$ & $\begin{array}{l}20 \\
\text { meter }\end{array}$ & $O F F$ & MATI \\
\hline 9. & $\begin{array}{l}\text { Lampu } \\
\text { Ruang } \\
\text { Tamu }\end{array}$ & $10 \mathrm{~km}$ & $O N$ & NYALA \\
\hline 10. & $\begin{array}{l}\text { Lampu } \\
\text { Kamar }\end{array}$ & $10 \mathrm{~km}$ & $O F F$ & MATI \\
\hline 11. & $\begin{array}{l}\text { Lampu } \\
\text { Ruang } \\
\text { Tamu }\end{array}$ & $10 \mathrm{~km}$ & $O N$ & NYALA \\
\hline 12. & $\begin{array}{l}\text { Lampu } \\
\text { Kamar }\end{array}$ & $10 \mathrm{~km}$ & $O F F$ & MATI \\
\hline 13. & $\begin{array}{l}\text { Lampu } \\
\text { Ruang } \\
\text { Tamu }\end{array}$ & $24 \mathrm{~km}$ & ON & NYALA \\
\hline 14. & $\begin{array}{l}\text { Lampu } \\
\text { Kamar }\end{array}$ & $24 \mathrm{~km}$ & $O F F$ & MATI \\
\hline 15. & $\begin{array}{l}\text { Lampu } \\
\text { Ruang } \\
\text { Tamu }\end{array}$ & $24 \mathrm{~km}$ & ON & NYALA \\
\hline 16. & $\begin{array}{l}\text { Lampu } \\
\text { Kamar }\end{array}$ & $24 \mathrm{~km}$ & $O F F$ & MATI \\
\hline
\end{tabular}

\section{Kesimpulan dan Saran \\ 5.1 Kesimpulan}

Berdasarkan implementasi dan pengujian yang telah dilakukan terhadap sistem kendali jarak jauh lampu menggunakan ThingsBoard berbasis IoT maka dapat diambil kesimpulan unjuk kerja dari Rancang Bangun Sistem Kendali Jarak Jauh Lampu Menggunakan Thingsboard Berbasis IoT menggunakan jaringan wifi. NodeMCU berperan penting dalam sistem kendali jarak jauh lampu untuk pengiriman data ke server ThingsBoard melalui jaringan wifi. Sistem kendali jarak jauh lampu akan dapat berjalan apabila nodemcu dan perangkat untuk 
kendali (smartphone atau komputer) berada dalam satu jaringan wifi. Lampu dapat menyala sesuai perintah menggunaan tombol dari web server Thingsboard. Jangka waktu nyala lampu dan tombol kendali pada ThingsBoard ditekan tidak ada jeda meskipun dari jarak $24 \mathrm{~km}$, namun jika jaringan internet tidak stabil maka membutuhkan waktu sekitar 30 detik hingga jaringan internet kembali stabil.

\subsection{Saran}

Pada pembuatan sistem kendali jarak jauh ini masih memiliki beberapa kekurangan sehingga memelukan masuk-masukan dari banyak pihak. Saran yang membangun dibutuhkan sebagai langkah pengembangan perbaikan serta penyempurnaan sistem ini.

1. Sistem kendali ini tidak bisa berjalan apabila jaringan wifi mati.

2. Tampilan antar muka tombol kontrol pada Thingsboard tidak biasa diubah-ubah.

\section{Daftar Pustaka}

Agam, Bima Brilliando dkk. Pengaruh Jenis Dan Bentuk Lampu Terhadap Intensitas Pencahayaan Dan Energi Buangan Melalui Perhitungan Nilai Efikasi Luminus. Jurnal Pendidikan Fisika. Vol. 3 No.4. 384 - 389.

Alfannizar, Ibnu, dkk. 2018. Perancangan dan Pembuatan Alat Home Electricity Based Home Appliance Controller Berbasis Internet of Things. Jom FTEKNIK. Vol.5, No.1. 1-6.

Alfaviega S.P. 2018. Sistem Monitoring Kadar Gas Berbahaya Berdasarkan Amonia Dan Metana Pada Peternakan Ayam Broiler Menggunakan Protokol MQTT Pada Realtime System. Jurnal Pengembangan Teknologi Informasi dan Ilmu Komputer. Vol. 2, No.10. 4056-4063.

Artono, Budi, dkk. 2017. Penerapan Internet Of Things (Iot) Untuk Kontrol Lampu Menggunakan Arduino Berbasis Web. Vol. 05, No 01. 9-16.

B. Gustomo. 2015. Pengenalan Arduino dan Pemrogrammannya. Bandung: Informatika Bandung.

Budioko, Totok. 2016. Sistem Monitoring Suhu Jarak Jauh Berbasis Internet Of Things Menggunakan Protokol Mqtt. Seminar Riset Teknologi Informasi (SRITI). 553-358.

Cahyono, G. H., 2015. Internet of Things. Forum Teknologi, Vol.06 No.3, 35-41.

Chamim, Anna Nur Nazilah, 2010. Penggunaan Mikrokontroller Sebagai Pendeteksi Posisi dengan menggunakan Sinyal GSM. Jurnal Informatika. Vol.4, No.1. 430-439.

Efendi, Yoyon. 2018. Internet of Things (Iot) Sistem Pengendalian Lampu Menggunakan Raspberry
Pi Berbasis Mobile. Jurnal Ilmiah Ilmu Komputer. Vol. 4, No. 1, 19-26.

Immersalab (2014, 10 Juli). Pengenalan Mikrokontroler. Di akses pada 22 Januari 2020, dari https://www.immersa-lab.com/pengenalanmikrokontroler.htm .

Iswanto, dkk. 2018. Perancangan Dan Implementasi Sistem Kendali Lampu Ruangan Berbasis Iot (Internet of Things) Android (Studi Kasus Universitas Nurtanio). Jurnal Teknologi Informasi dan Komunikasi. Vol.9, No. 1. 38-46.

K, Anggraini, dkk. 2017. Pemanfaatan Internet Of Things Pada Kendali Lampu. Vol.6, No.1. 53-59.

Ma'mur, Muhammad, dkk. 2018. Sistem Kendali Lampu Jarak Jauh Berbasis Web. Jurnal Cendikia. Vol.16. 140-145.

Mahali, Muhammad Izzuddin. 2016. Smart Door Locks Based on Internet of Things Concept with Mobile Backend as A Service. Jurnal Electronics, Informatics, and Vocational Education (ELINVO). Vol.1 No. 3, 171-181.

Prihatmoko, Dias. 2016. Penerapan Internet Of Things ( Iot ) Dalam Pembelajaran Di Unisnu Jepara. Jurnal SIMETRIS. Vol 7, No 2. 567-574.

Saleh, Muhammad, dkk. 2017. Rancang Bangun Sistem Keamanan Rumah Menggunakan Relay. Jurnal Teknologi Elektro. Vol. 8 No. 2. 87 - 94.

Sanad, Ali, dkk. 2018. Perancangan Sistem Dan Monitoring Penerangan Lampu Otomatis di Tempat Parkir Berbasis Internet of Things (Iot). e-Proceeding of Engineering. Vol.5, No.3. 41004111.

Saputro, Jimy Harto dkk. Analisa Penggunaan Lampu Led Pada Penerangan Dalam Rumah. TRANSMISI. Vol 15, No 1. 20-27.

Satya, Ellian Adhi, dkk. 2016. Pengontrolan Lampu Melalui Internet Menggunakan Mikrokontroller Arduino Berbasis Android. TRANSIENT. Vol.5, No.3. 358-367.

Setiadi, David, dkk. 2018. Penerapan Internet Of Things (Iot) Pada Sistem Monitoring Irigasi (Smart Irigasi). Jurnal Infotronik. Volume 3, No. 2. 95-102.

Susanto, Bekti Maryuni, dkk. 2018. Implementasi Mqtt Protocol Pada Smart Home Security Berbasis Web. Jurnal Informatika Polinema. Volume 4, Edisi 3. 201-205.

Sutono. Perancangan Sistem Aplikasi Otomatisasi Lampu Penerangan Menggunakan Sensor Gerak Dan Sensor Cahaya Berbasis Arduino Uno (Atmega 328). Majalah Ilmiah UNIKOM. Vol.12 No. 2, 223 - 232. 
Volume 7, Edisi 1, November 2020

36| H a 1 a $m$ a n 